\title{
Sistem Pendukung Keputusan Penentuan Instruktur Bahasa Inggris Dengan Metode Simple Additive Weighting (SAW)
}

\author{
Hery Sunandar ${ }^{* 1}$, Denni M Rajagukguk ${ }^{2}$ \\ ${ }^{1}$ STMIK Budi Darma Medan, Jl. Sisingamangaraja No. 338 Simpang Limun Medan, Indonesia ${ }^{2}$ Universitas Imelda Medan, Jl. \\ Bilal Ujung No.24,52, Pulo Brayan Darat I, Medan Timur, Indonesia hery.nandar@gmail.com ${ }^{1}$, rajdenni@yahoo.co.id ${ }^{2}$
}

\begin{abstract}
Abstrak-Penggunaan Sistem Pendukung Keputusan (SPK) dapat membantu seseorang dalam mengambil keputusan yang akurat dan tepat sasaran. Banyak permasalahan yang dapat diselesaikan dengan menggunakan SPK. Penelitian ini bertujuan untuk merancang SPK dengan Metode SAW untuk penentuan instruktur Bahasa Inggris. Sistem ini memanfaatkan kriteria-kriteria dan bobot. Terdapat 6 kriteria utama untuk pengukur. Berdasarkan analisa SPK dengan menggunakan metode SAW diperoleh hasil efektivitas kinerja. Berdasarkan metode SAW efektivitas penentuan instruktur bahasa Inggris dipengaruhi oleh banyak faktor yang menjadi kriteria dari sistem pendukung keputusan itu.
\end{abstract}

Kata kunci: SPK, Metode SAW.

Abstract-Use of Decision Support Systems (SPK) can help someone in making decisions that are accurate and right on target. Many problems can be solved by using SPK. This study aims to design SPK with SAW Method for the determination of English instructors. This system utilizes criteria and weights. There are 6 main criteria for gauges. Based on the SPK analysis using the SAW method the results of performance effectiveness are obtained. Based on the SAW method the effectiveness of the determination of the English instructor is influenced by many factors that are the criteria of the decision support system.

Keywords: SPK, SAW Method.

\section{PENDAHULUAN}

Kemajuan teknologi yang sangat dirasakan oleh badan-badan organisasi yang banyak menghasilkan dan membutuhkan informasi dalam kegiatan operasionalnya, karena disadari bahwa komputer merupakan alat Bantu untuk menyelesaikan berbagai pekerjaan manusia secara cepat dan tepat. Di samping itu komputer juga dapat menyimpan data, memperbaiki data, serta mengambil informasi yang diinginkan, dimana data dan informasi tersebut disimpan dalam suatu media penyimpanan berupa file[1].

Konsep dan aplikasi sistem pendukung keputusan, konsep sistem pengambilan keputusan (SPK) yang berkembang pesat, menimbulkan beberapa metode untuk menciptakan permodelan sebagai sarana pengambilan keputusan dengan kelebihan dan kekurangannya masing-masing[2]. Diantaranya AHP (Analytic Hierarchy Process) yang digunakan untuk pengambilan keputusan dalam hal melakukan prediksi atas suatu produk, IRR (Internal Rate Of Return) yang digunakan untuk pengambilan keputusan berdasarkan analisa ekonomi, Kuantitatif yang melakukan keputusan berdasarkan nilai matematis.

Metode Simple Additive Weighting (SAW) sering juga dikenal istilah metode penjumlahan terbobot. Konsep dasar metode SAW adalah mencari penjumlahan terbobot dari rating kinerja pada setiap alternatif pada semua atribut Metode SAW membutuhkan proses normalisasi matriks keputusan (X) ke suatu skala yang dapat diperbandingkan dengan semua rating alternatif yang ada. Metode ini merupakan metode yang paling terkenal dan paling banyak digunakan dalam menghadapi situasi Multiple Attribute Decision Making (MADM). MADM itu sendiri merupakan suatu metode yang digunakan untuk mencari alternatif optimal dari sejumlah alternatif dengan kriteria tertentu[3]. Metode SAW ini mengharuskan pembuat keputusan menentukan bobot bagi setiap atribut. Skor total untuk alternatif diperoleh dengan menjumlahkan seluruh hasil perkalian antara rating (yang dapat dibandingkan lintas atribut) dan bobot tiap atribut. Rating tiap atribut haruslah bebas dimensi dalam arti telah melewati proses normalisasi matriks sebelumnya.

Sistem Pendukung Keputusan (SPK) / Decision Support System (DSS) merupakan sistem informasi interaktif yang menyediakan informasi, pemodelan, dan pemanipulasian data. Sistem ini digunakan untuk membantu pengambilan keputusan dalam situasi yang semiterstruktur dan situasi yang tidak terstruktur, di mana tak seorangpun tahu secara pasti bagaimana keputusan seharusnya dibuat.

Decision Support System (DSS) biasanya dibangun untuk mendukung solusi atas suatu masalah atau untuk mengevaluasi suatu peluang. Decision Support System (DSS) yang seperti itu disebut aplikasi Decision Support System (DSS). Aplikasi Decision Support System (DSS) digunakan dalam pengambilan keputusan. Aplikasi Decision Support System (DSS) menggunakan CBIS (Computer Based Information Systems) yang fleksibel, interaktif, dan dapat diadaptasi, yang dikembangkan untuk mendukung solusi atas masalah manajemen spesifik yang tidak terstruktur. Aplikasi Decision Support System (DSS) menggunakan data, memberikan antarmuka pengguna yang mudah, dan dapat menggabungkan pemikiran pengambilan 
keputusan. Dari sisi konteks, pada dasarnya sebuah sistem pendukung keputusan akan lebih dikenal apabila mengetahui terlebih dahulu pengertian dan manfaat sebuah sistem. Lebih lanjut pengertian tentang sistem pertama kali dapat diperoleh dari defenisinya sebagai suatu prosedur atau aturan atau sering disebut tahap dan cara. Dengan demikian defenisi ini akan mempunyai peranan penting didalam pendekatan untuk mempelajari suatu sistem. Pendekatan sistem yang merupakan kumpulan dari elemen-elemen atau komponen-komponen atau subsistem-subsistem merupakan defenisi yang luas. Defenisi ini lebih banyak diterima, karena kenyataan suatu sistem dapat terdiri dari beberapa subsistem atau sistem bagian lainnya[4][5].

\section{METODE PENELITIAN}

Metode penelitian yang digunakan dalam menentukan instruktur Bahasa Inggris pada penelitian ini dengan tahap-tahap sebagai berikut [6]:

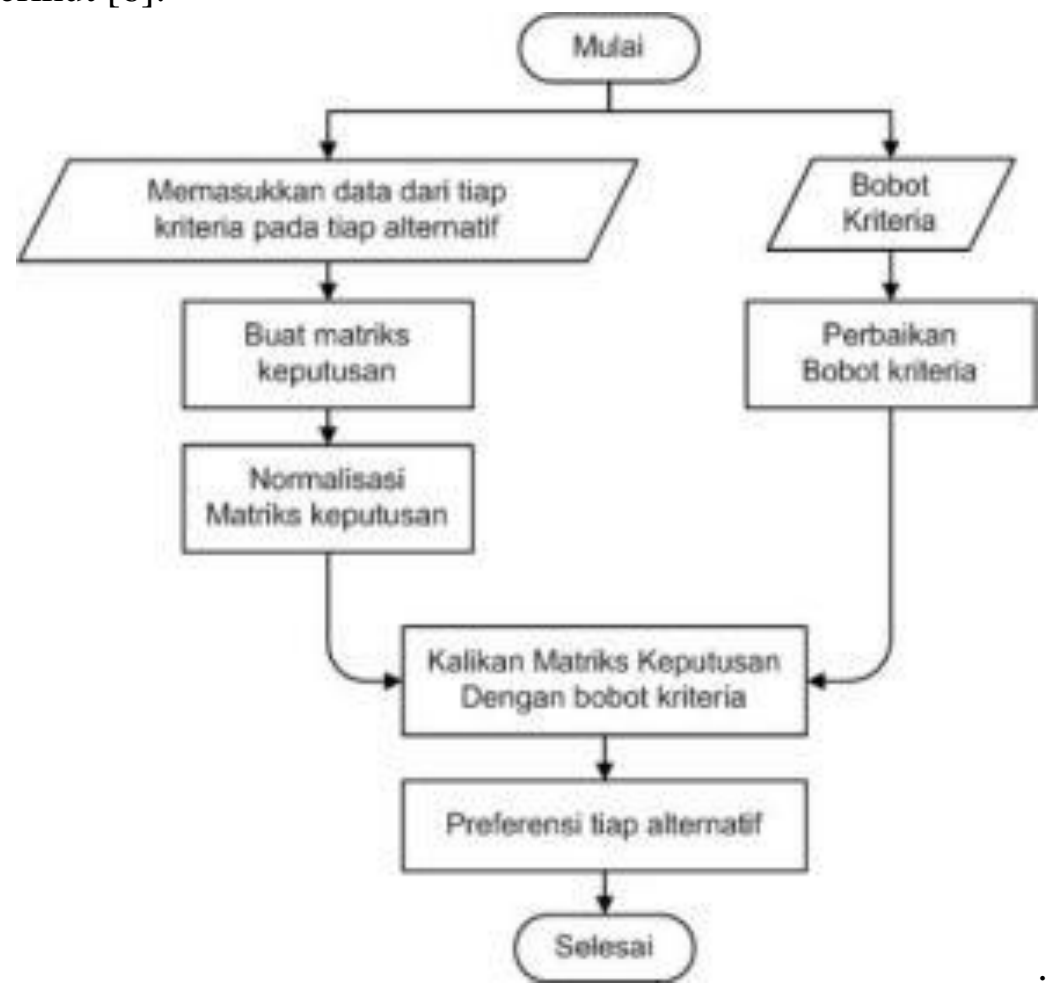

Gambar 1. Metode Penelitian

Metode SAW sering juga dikenal istilah metode penjumlahan terbobot. Konsep dasar metode SAW adalah mencari penjumlahan terbobot dari rating kinerja pada setiap alternatif pada semua atribut. Metode SAW membutuhkan proses normalisasi matriks keputusan $(\mathrm{X})$ ke suatu skala yang dapat diperbandingkan dengan semua rating alternatif yang ada.Metode ini merupakan metode yang paling dikenal dan paling banyak digunakan orang dalam menghadapi situasi MADM. Metode ini mengharuskan pembuat keputusan menentukan bobot bagi setiap atribut. Skor total untuk sebuah alternatif diperoleh dengan menjumlahkan seluruh hasil perkalian antara rating (yang dapat dibandingkan lintas atribut) dan bobot tiap atribut. Rating tiap atribut haruslah bebas dimensi yang artinya telah melewati proses normalisasi sebelumnya[7].

Langkah-langkah penyelesaian dengan metode SAW yaitu:

1. Menentukan kriteria-kriteria yang akan dijadikan acuan dalam pengambilan keputusan, yaitu Ci.

2. Menentukan rating kecocokan setiap alternatif pada setiap kriteria.

3. Membuat matriks keputusan berdasarkan kriteria (Ci), kemudian melakukan normalisasi matriks berdasarkan persamaan yang disesuaikan dengan jenis atribut (atribut keuntungan ataupun atribut biaya) sehingga diperoleh matriks ternormalisasi R.

4. Hasil akhir diperoleh dari proses perankingan yaitu penjumlahan dari perkalian matriks ternormalisasi $\mathrm{R}$ dengan vektor bobot sehingga diperoleh nilai terbesar yang dipilih sebagai alternatif terbaik $\left(\mathrm{A}_{\mathrm{i}}\right)$

Metode SAW membutuhkan proses normalisasi matriks keputusan (X) ke suatu skala yang dapat diperbandingkan dengan semua rating alternatif yang ada. Formula untuk melakukan normalisasi tersebut adalah sebagai berikut [8], [9]: 


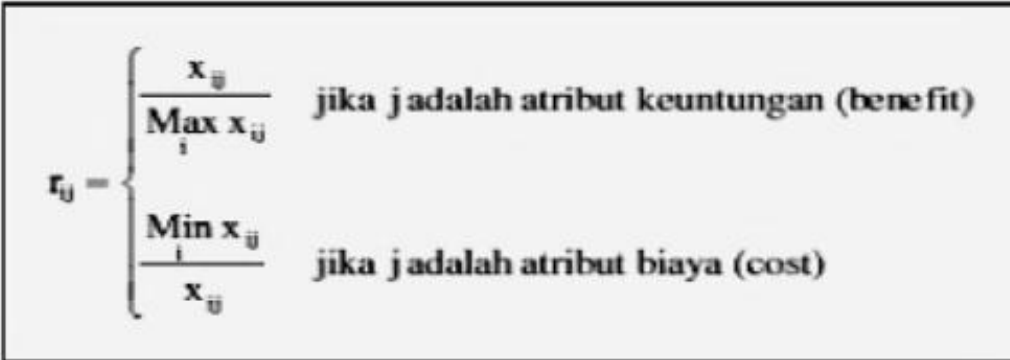

dengan $r_{i j}$ adalah rating kinerja ternormalisasi dari alternatif $A_{i}$ pada atribut $C_{j} ; i=1,2, \ldots, m$ dan $j=1,2, \ldots, n$. - Nilai preferensi untuk setiap alternatif $\left(\mathrm{V}_{\mathrm{i}}\right)$ diberikan sebagai:

$$
\mathbf{V}_{\mathrm{i}}=\sum_{\mathrm{j}=1}^{\mathrm{n}} \mathbf{w}_{\mathrm{j}} \mathbf{r}_{\mathrm{ij}}
$$

- Nilai $V_{i}$ yang lebih besar mengindikasikan bahwa alternatif $A_{i}$ lebih terpilih.

\subsection{Data yang digunakan}

\section{HASIL DAN PEMBAHASAN}

Model SAW dalam prosesnya memerlukan kriteria yang akan dijadikan bahan perhitungan pada proses perankingan. Kriteria yang menjadi bahan pertimbangan bagian proses penentuan instruktur bahasa Inggris seperti yang ditunjukan pada tabel 1.

Tabel 1. Kriteria

\begin{tabular}{|c|l|}
\hline Kriteria & \multicolumn{1}{|c|}{ Keterangan } \\
\hline $\mathrm{C} 1$ & Pendidikan \\
\hline $\mathrm{C} 2$ & Umur \\
\hline $\mathrm{C} 3$ & Nilai Wawancara \\
\hline $\mathrm{C} 4$ & Pengalaman Kerja \\
\hline $\mathrm{C} 5$ & Nilai Test Bahasa Inggris \\
\hline $\mathrm{C} 6$ & Nilai Psikotest \\
\hline
\end{tabular}

\subsection{Proses}

Langkah penyelesaian dalam penerapan metode Simple Additive Weighting (SAW) meliputi:

1. Memberikan nilai setiap alternatif (Ai) pada setiap kriteria (Cj) yang sudah ditentukan. Hasil dapat dikonversikan ke bilangan crisp. Untuk lebih jelas data pendidikan dibentuk dalam tabel 2 di bawah ini Tabel 2. Pendidikan

\begin{tabular}{|c|c|}
\hline Bilangan Fuzzy & Nilai \\
\hline D3 & 0.57 \\
\hline S1 & 0.71 \\
\hline S2 & 0.86 \\
\hline S3 & 1 \\
\hline
\end{tabular}

a. Umur

Pada variabel usia bilangan-bilangan dapat dikonversikan ke bilangan crisp. Untuk lebih jelas data umur dibentuk dalam tabel 3

Tabel 3. Umur

\begin{tabular}{|c|c|}
\hline Umur & Nilai \\
\hline$<=18$ Tahun & 0.25 \\
\hline $\begin{array}{c}>=19 \text { s/d }<=22 \\
\text { Tahun }\end{array}$ & 0.5 \\
\hline $\begin{array}{c}>=23 \text { s/d }<=26 \\
\text { Tahun }\end{array}$ & 0.75 \\
\hline$>26$ Tahun & 1 \\
\hline
\end{tabular}

b. Nilai Wawancara 
Pada variabel nilai wawancara dapat dikonversikan ke bilangan crisp. Untuk lebih jelas data nilai wawancara dibentuk dalam tabel 4.

Tabel 4. Nilai Wawancara

\begin{tabular}{|c|c|}
\hline Nilai Wawancara & Nilai \\
\hline $0-25$ & 0.25 \\
\hline $26-50$ & 0.5 \\
\hline $51-75$ & 0.75 \\
\hline $76-100$ & 1 \\
\hline
\end{tabular}

c. Pengalaman Kerja

Pada variabel Pengalaman Kerja dapat dikonversikan ke bilangan crisp. Untuk lebih jelas data Nilai Wawancara dibentuk dalam tabel 5.

Tabel 5 Pengalaman Kerja

\begin{tabular}{|c|c|}
\hline Lama & Nilai \\
\hline 0 tahun & 0 \\
\hline 1 Tahun & 0.25 \\
\hline$>=2$ s/d <=3 Tahun & 0.5 \\
\hline$>=4$ s/d <=6 Tahun & 0.75 \\
\hline$>6$ Tahun & 1 \\
\hline
\end{tabular}

d. Nilai Test Bahasa Inggris

Pada variabel Nilai Test Bahasa dapat dikonversikan ke bilangan. Untuk lebih jelas data Nilai

Wawancara dibentuk dalam tabel 6.

Tabel 6 Nilai Test Bahasa Inggris

\begin{tabular}{|c|c|}
\hline Nilai & Nilai \\
\hline $0 \mathrm{~s} / \mathrm{d} 50$ & 0 \\
\hline $51 \mathrm{~s} / \mathrm{d} 59$ & 0.25 \\
\hline $60 \mathrm{~s} / \mathrm{d} 69$ & 0.5 \\
\hline $70 \mathrm{~s} / \mathrm{d} 79$ & 0.75 \\
\hline$>=80$ & 1 \\
\hline
\end{tabular}

e. Nilai Psikotest

Pada variabel Nilai Psikotest dapat dikonversikan ke bilangan. Untuk lebih jelas data Nilai Wawancara dibentuk dalam tabel 7.

Tabel 7. Nilai Psikotest

\begin{tabular}{|c|c|}
\hline Nilai & Nilai \\
\hline 0 s/d 50 & 0 \\
\hline 51 s/d 59 & 0.25 \\
\hline 60 s/d 69 & 0.5 \\
\hline 70 s/d 79 & 0.75 \\
\hline$>=80$ & 1 \\
\hline
\end{tabular}

Agar lebih jelas dimisalkan untuk dari Tabel 4.8 diatas adalah $\mathrm{K} 1=$ Instruktur A, K2 = Instruktur B dan $\mathrm{K} 3$ = Instruktur C. Tabel 8 menunjukkan rating kecocokan dari setiap alternatif pada setiap kriteria.

Tabel 8. Rating kecocokan dari setiap alternatif pada setiap kriteria.

\begin{tabular}{|c|c|c|c|c|c|c|}
\hline \multirow{2}{*}{$\begin{array}{c}\text { Altern } \\
\text { atif }\end{array}$} & \multicolumn{7}{|c|}{ Kriteria } \\
\cline { 2 - 7 } & $\mathrm{C} 1$ & $\mathrm{C} 2$ & $\mathrm{C} 3$ & $\mathrm{C} 4$ & $\mathrm{C} 5$ & $\mathrm{C} 6$ \\
\hline K1 & 0.29 & 0.5 & 0.75 & 0.25 & 0.75 & 0.75 \\
\hline K2 & 0.57 & 0.75 & 0.5 & 0.5 & 0.75 & 0.75 \\
\hline K3 & 0.71 & 0.75 & 0.75 & 0.5 & 1 & 1 \\
\hline
\end{tabular}

Dari Tabel 8 diubah kedalam matriks keputusan X dengan data :

$$
X=\left[\begin{array}{llllll}
0.29 & 0.5 & 0.75 & 0.25 & 0.75 & 0.75 \\
0.57 & 0.75 & 0.5 & 0.5 & 0.75 & 0.75 \\
0.71 & 0.75 & 0.75 & 0.5 & 1 & 1
\end{array}\right]
$$


2. Memberikan nilai bobot (W).

Untuk menentukan bobot dari penentuan Instruktur dibentuk dalam tabel 9

Tabel 9 Bobot untuk Penentuan Instruktur

\begin{tabular}{|l|c|c|}
\hline \multicolumn{1}{|c|}{ Kriteria } & Bobot & Nilai \\
\hline C1 (Pendidikan) & Rendah (R) & 0.2 \\
\hline C2 (Umur) & Rendah (R) & 0.2 \\
\hline C3 (Nilai Wawancara) & Sedang (S) & 0.4 \\
\hline C4 (Pengalaman Kerja) & Sedang (S) & 0.4 \\
\hline C5 (Nilai Test Bahasa Inggris) & Tengah (T1) & 0.6 \\
\hline C6 (Nilai Psikotest) & Tengah (T1) & 0.6 \\
\hline
\end{tabular}

Dari Tabel 4.10 diperoleh nilai bobot (W) dengan data :

$$
\mathrm{W}=\left[\begin{array}{llllll}
0.2 & 0.2 & 0.4 & 0.4 & 0.6 & 0.6
\end{array}\right]
$$

3. Menormalisasi matriks $\mathrm{X}$ menjadi matriks $\mathrm{R}$ berdasarkan persamaan 1 .

$$
r_{i j}=\left\{\begin{array}{l}
\frac{x_{i j}}{\operatorname{Max} X_{i j}} \text { Jika } \mathrm{j} \text { adalah atribut diterima } \\
\frac{\operatorname{Min}_{i} X_{i j}}{X_{i j}} \mathrm{Jika} \mathrm{i} \text { adalah atribut ditolak }
\end{array}\right.
$$

Keterangan :

$\mathrm{rij}_{\mathrm{ij}}=$ nilai rating kinerja ternormalisasi

$\mathrm{X}$ ij = nilai atribut yang dimiliki setiap kriteria

$\operatorname{maxi} \mathrm{X}_{\mathrm{ij}}=$ nilai terbesar dari setiap kriteria

$\min _{\mathrm{i}} \mathrm{X}_{\mathrm{ij}}=$ nilai terkecil dari setiap kriteria.

benefit $=$ jika nilai terbesar adalah terbaik .

$\cos t=$ jika nilai terkecil adalah terbaik.

Tabel 10 Penggolongan kriteria

\begin{tabular}{|l|c|c|}
\hline \multicolumn{1}{|c|}{ Kriteria } & Cost & Benefit \\
\hline C1 (Pendidikan) & & $\checkmark$ \\
\hline C2 (Umur) & $\checkmark$ & \\
\hline C3 (Nilai Wawancara) & & $\checkmark$ \\
\hline C4 (Pengalaman Kerja) & & $\checkmark$ \\
\hline C5 (Nilai Test Bahasa Inggris) & & $\checkmark$ \\
\hline C6 (Nilai Psikotest) & & $\checkmark$ \\
\hline
\end{tabular}

a. Untuk pendidikan termasuk ke dalam atribut keuntungan (benefit), karena semakin tinggi nilai maka dianggap semakin baik.

$$
\begin{aligned}
& r_{11}=\frac{0.29}{\operatorname{Max}\{0.29 ; 0.43 ; 0.57 ; 0.71 ; 86 ; 1\}}=\frac{0.29}{1}=0.29 \\
& r_{21}=\frac{0.57}{\operatorname{Max}\{0.29 ; 0.43 ; 0.57 ; 0.71 ; 86 ; 1\}}=\frac{0.29}{1}=0.29 \\
& r_{31}=\frac{0.71}{\operatorname{Max}\{0.29 ; 0.43 ; 0.57 ; 0.71 ; 86 ; 1\}}=\frac{0.71}{1}=0.71
\end{aligned}
$$

b. Untuk umur termasuk ke dalam atribut biaya (cost), karena semakin kecil nilai maka dianggap semakin

$$
\begin{aligned}
& r_{11}=\frac{\operatorname{Min}\{0.25 ; 0.5 ; 0.75 ; 1\}}{0.5}=\frac{0.25}{0.5}=0.50 \\
& r_{21}=\frac{\operatorname{Min}\{0.25 ; 0.5 ; 0.75 ; 1\}}{0.75}=\frac{0.25}{0.75}=0.33 \\
& r_{31}=\frac{\operatorname{Min}\{0.25 ; 0.5 ; 0.75 ; 1\}}{0.75}=\frac{0.25}{0.75}=0.33
\end{aligned}
$$


c. Untuk Nilai Wawancara termasuk ke dalam atribut keuntungan (benefit), karena semakin tinggi nilai maka dianggap semakin baik.

$$
\begin{aligned}
& r_{11}=\frac{0.75}{\operatorname{Max}\{0.29 ; 0.43 ; 0.57 ; 0.71 ; 86 ; 1\}}=\frac{0.75}{1}=0.75 \\
& r_{21}=\frac{0.5}{\operatorname{Max}\{0.29 ; 0.43 ; 0.57 ; 0.71 ; 86 ; 1\}}=\frac{0.5}{1}=0.5 \\
& r_{31}=\frac{0.75}{\operatorname{Max}\{0.29 ; 0.43 ; 0.57 ; 0.71 ; 86 ; 1\}}=\frac{0.75}{1}=0.75
\end{aligned}
$$

d. Untuk pengalaman kerja termasuk ke dalam atribut keuntungan (benefit), karena semakin tinggi pengalaman kerja maka dianggap semakin baik.

Jadi:

$$
\begin{aligned}
& r_{11}=\frac{0.25}{\operatorname{Max}\{0.29 ; 0.43 ; 0.57 ; 0.71 ; 86 ; 1\}}=\frac{0.25}{1}=0.25 \\
& r_{21}=\frac{0.5}{\operatorname{Max}\{0.29 ; 0.43 ; 0.57 ; 0.71 ; 86 ; 1\}}=\frac{0.5}{1}=0.5 \\
& r_{31}=\frac{0.5}{\operatorname{Max}\{0.29 ; 0.43 ; 0.57 ; 0.71 ; 86 ; 1\}}=\frac{0.5}{1}=0.5
\end{aligned}
$$

e. Untuk Nilai Test Bahasa Inggris termasuk ke dalam atribut keuntungan (benefit), karena semakin tinggi nilai test bahasa Inggris maka dianggap semakin baik.

Jadi :

$$
\begin{aligned}
& r_{11}=\frac{0.75}{\operatorname{Max}\{0.29 ; 0.43 ; 0.57 ; 0.71 ; 86 ; 1\}}=\frac{0.75}{1}=0.75 \\
& r_{21}=\frac{0.75}{\operatorname{Max}\{0.29 ; 0.43 ; 0.57 ; 0.71 ; 86 ; 1\}}=\frac{0.75}{1}=0.75 \\
& r_{31}=\frac{1}{\operatorname{Max}\{0.29 ; 0.43 ; 0.57 ; 0.71 ; 86 ; 1\}}=\frac{1}{1}=1
\end{aligned}
$$

f. Untuk Nilai Psikotest termasuk ke dalam atribut keuntungan (benefit), karena semakin tinggi nilai psikotest maka dianggap semakin baik.

$$
\begin{aligned}
& r_{11}=\frac{0.75}{\operatorname{Max}\{0.29 ; 0.43 ; 0.57 ; 0.71 ; 86 ; 1\}}=\frac{0.75}{1}=0.75 \\
& r_{21}=\frac{0.75}{\operatorname{Max}\{0.29 ; 0.43 ; 0.57 ; 0.71 ; 86 ; 1\}}=\frac{0.75}{1}=0.75 \\
& r_{31}=\frac{1}{\operatorname{Max}\{0.29 ; 0.43 ; 0.57 ; 0.71 ; 86 ; 1\}}={ }_{-1}=1
\end{aligned}
$$

Matrik R :

$\mathrm{R}=\left[\begin{array}{cccccc}0.29 & 0.50 & 0.75 & 0.25 & 0.75 & 0.75 \\ 0.29 & 0.50 & 0.5 & 0.5 & 0.75 & 0.75 \\ 0.71 & 0.33 & 0.75 & 0.5 & 1 & 1\end{array}\right]$

4. Melakukan proses perankingan dengan menggunakan persamaan

$$
V_{i}=\sum_{j=1}^{n} W \underset{j i j}{r}
$$

Keterangan :

$\mathrm{V}_{\mathrm{i}}=$ ranking untuk setiap alternatif

$\mathrm{W}_{\mathrm{j}}=$ nilai bobot dari setiap criteria

$\mathrm{rij}_{\mathrm{ij}}=$ nilai rating kinerja ternormalisasi 


$\begin{aligned} \mathrm{W} & =\left[\begin{array}{lllllr}0.2 & 0.2 & 0.4 & 0.4 & 0.6 & 0.6\end{array}\right] \\ \mathrm{R} & =\left[\begin{array}{lllllr}0.29 & 0.50 & 0.75 & 0.25 & 0.75 & 0.75 \\ 0.29 & 0.50 & 0.5 & 0.5 & 0.75 & 0.75 \\ 0.71 & 0.33 & 0.75 & 0.5 & 1 & 1\end{array}\right]\end{aligned}$

Maka,

$$
\begin{aligned}
\mathrm{V}_{1} & =(0.29)(0.2)+(0.5)(0.2)+(0.5)(0.4)+(0.25)(0.4)+(0.75)(0.6)+(0.75)(0.6) \\
& =0,058+0,1+0,2+0,1+0,45+0,45 \\
& =1,358 \\
\mathrm{~V}_{2} & =(0.29)(0.2)+(0.5)(0.2)+(0.5)(0.4)+(0.50)(0.4)+(0.75)(0.6)+(0.75)(0.6) \\
& =0,058+0,1+0,2+0,2+0,45+0,45 \\
& =1,458 \\
\mathrm{~V}_{3} & =(0.71)(0.2)+(0.33)(0.2)+(0.75)(0.4)+(0.5)(0.4)+(0.75)(0.6)+(0.75)(0.6) \\
& =0,142+0,066+0,3+0.2+0.45+0.45 \\
& =1,608
\end{aligned}
$$

\subsection{Hasil}

Nilai terbesar ada pada V3 sehingga alternatif K3 (Instruktur 3) adalah alternatif yang terpilih sebagai alternatif terbaik. Maka Instruktur K3 terpilih untuk menjadi Instruktur. Untuk lebih jelas lihat pada Tabel 11.

Tabel 11. Ranking

\begin{tabular}{|c|c|c|c|c|c|c|c|c|}
\hline No & $\begin{array}{c}\text { Nama } \\
\text { Calon } \\
\text { Instruktur }\end{array}$ & Pendidikan & Umur & $\begin{array}{c}\text { Nilai } \\
\text { Wawancara }\end{array}$ & $\begin{array}{c}\text { Pengalaman } \\
\text { Kerja }\end{array}$ & $\begin{array}{c}\text { Nilai } \\
\text { Test } \\
\text { Bahasa } \\
\text { Inggris }\end{array}$ & $\begin{array}{c}\text { Nilai } \\
\text { Psikotest }\end{array}$ & $\begin{array}{c}\text { Hasil } \\
\text { Akhir }\end{array}$ \\
\hline 1 & K3 & 0.71 & 0.75 & 0.75 & 0.5 & 1 & 1 & 1.608 \\
\hline 2 & K2 & 0.57 & 0.75 & 0.5 & 0.5 & 0.75 & 0.75 & 1.458 \\
\hline 3 & K1 & 0.29 & 0.5 & 0.75 & 0.25 & 0.75 & 0.75 & 1.358 \\
\hline
\end{tabular}

\section{KESIMPULAN}

Aplikasi yang dibangun dapat membantu dalam penentuan Instruktur Bahasa Inggris menggunakan metode Fuzzy Multiple Criteria Decision Making dengan perhitungan bobot menggunakan Simple Addaptive Weigthing sebagai acuan penentuan instruktur Bahasa Inggris.

\section{DAFTAR PUSTAKA}

[1] H. M. Jogiyanto, Analisis dan Desain (Sistem Informasi Pendekatan Terstruktur Teori dan Praktek Aplikasi Bisnis). Yogyakarta: Penerbit Andi, 2017.

[2] Kusrini, Konsep dan Aplikasi Sistem Pendukung Keputusan. 2007.

[3] T. Limbong et al., "The Implementation of Multi-Objective Optimization on the Basis of Ratio Analysis Method to Select the Lecturer Assistant Working at Computer Laboratorium," 2018.

[4] K. Nisa and E. Sutinah, "Profile Matching Untuk Sistem Pendukung Keputusan Pemilihan Vendor Maintenance Server dan Jaringan," J. Inform., vol. 5, no. 2, pp. 262-269, 2018, doi: 10.31311/ji.v5i2.3638.

[5] T. Limbong, "Pemanfaatan visualisasi dan animasi untuk kegiatan akademik sebagai sarana pengumuman pada stmik budi darma medan," Inf. dan Teknol. Ilm., 2013.

[6] Sugiyono, Metode Penelitian Kuantitatif, Kualitatif dan R\&D. Bandung: PT Alfabet, 2016.

[7] A. Rikki, "Pengujian Sistem Pendukung Keputusan Metode Simple Additive Weighting dan Weighted Product dengan Matlab," vol. 2, no. 1, pp. 47-51, 2017.

[8] J. Simarmata, T. Limbong, M. Aritonang, and S. Sriadhi, "SISTEM PENDUKUNG KEPUTUSAN PEMILIHAN GURU BIDANG STUDI KOMPUTER MENGGUNAKAN METODE SIMPLE ADDITIVE WEIGHTING (SAW)," Comput. Eng. Sci. Syst. J., vol. 3 , no. 2, pp. 186-190, 2018.

[9] S. Mahulae and T. Limbong, "Implementasi Metode Simple Additive Weighting dalam Penentuan Guru untuk diusulkan Sertifikasi," MEANS (Media Inf. Anal. dan Sist., vol. 4, no. 1, pp. 58-63, 2019. 